\title{
Crenças acerca do sistema de treinamento: a predição de variáveis pessoais e funcionais ${ }^{1}$
}

\section{Beliefs concerning the system of training: the prediction of personal and job-related variables}

\author{
Jesiane Marins LOPES ${ }^{2}$ \\ Luciana MOURÃO2
}

\begin{abstract}
Resumo
Pesquisas têm apontado as crenças sobre o Sistema de Treinamento, Desenvolvimento e Educação como importante variável preditora do impacto das ações de capacitação sobre o desempenho no trabalho. Porém, quais variáveis estão relacionadas às crenças sobre o sistema de Sistema de Treinamento, Desenvolvimento e Educação? O objetivo do presente estudo foi identificar quão positivas são as crenças sobre o sistema de treinamento e verificar se as características individuais influenciam essas crenças. A amostra de pesquisa foi de 220 sujeitos, que trabalham em sete empresas privadas do Estado do Rio de Janeiro. A escala utilizada na pesquisa havia sido previamente validada. Realizaram-se análises descritivas, correlações e regressões. Os resultados indicam que experiência prévia em Sistema de Treinamento, Desenvolvimento e Educação, idade, tempo de trabalho e salário são variáveis preditoras das crenças sobre o sistema de Sistema de Treinamento, Desenvolvimento e Educação. Foram discutidas implicações práticas dos resultados e sugerida uma agenda de pesquisa para a área.
\end{abstract}

Unitermos: Atitudes. Desempenho no trabalho. Diferenças individuais. Treinamento de pessoal.

\begin{abstract}
Research has shown beliefs in the System of Training, Development and Education to be an important, predictive variable of the impact of the actions of Training on performance at work. However, which variables are related to beliefs about the System of Training, Development and Education? The purpose of this study was to identify how good are the beliefs about the system of training and to ascertain if individual characteristics influence these beliefs. 220 individuals were included in the sample survey, working in seven private companies in Rio de Janeiro. The scale used in the survey had been previously validated. Descriptive analyses, correlations and regressions were conducted. The results indicate that previous experience in the System of Training, Development and Education, age, length of service and salary are determinants of beliefs concerning the System of Training, Development and Education. We discussed the practical implications of the results and suggested an agenda for research into this area.
\end{abstract}

Uniterms: Attitudes. Job performance. Individual differences. Personnel training.

$\operatorname{coth}$

1 Artigo elaborado a partir da dissertação de J.M. LOPES, intitulada "Avaliação de treinamento nos níveis de aprendizagem e reação: a influência da motivação para aprender e das crenças sobre o sistema de treinamento". Universidade Salgado de Oliveira, 2008.

2 Universidade Salgado de Oliveira, Pró-Reitoria de Pós-Graduação, Programa de Pós-Graduação em Psicologia. R. Marechal Deodoro, 263, Centro, 24030-060, Niterói, RJ, Brasil. Correspondência para/Correspondence to: L. MOURÃO. E-mail: <mourao.luciana@gmail.com>. 
Um dos avanços nas pesquisas sobre Treinamento, Desenvolvimento e Educação (TD\&E) diz respeito à identificação de fatores que afetam a sua eficácia. Os profissionais que atuam em gestão de pessoas necessitam conhecer melhor a forma como as pessoas lidam com as ações de capacitação e o que pode ser feito para aumentar seu efeito. A presente pesquisa objetivou conhecer as crenças sobre o sistema de treinamento e investigar quais variáveis individuais e funcionais são preditoras das crenças sobre TD\&E.

Pesquisa desenvolvida por Freitas (2005) mostrou que as crenças sobre o sistema de treinamento influenciam no impacto das ações de capacitação. Ou seja, de acordo com a crença que o treinando tenha sobre o sistema, ele irá aplicar no trabalho com maior ou menor intensidade aquilo que aprendeu nos eventos de TD\&E. Porém, ainda não se investigou que variáveis podem influenciar as crenças sobre o sistema de TD\&E. Considerando o objetivo exposto, foi realizada a presente pesquisa com funcionários de sete empresas privadas do Rio de Janeiro.

Para Borges-Andrade (1996), treinamento corresponde ao conjunto de partes coordenadas entre si, que tem como referencial o modelo sistêmico de compreensão do fenômeno organizacional, com três componentes interdependentes: avaliação de necessidades de capacitação, planejamento e execução do treinamento e avaliação. Essa definição deixa clara a visão sistêmica do treinamento que demanda interação tanto dos componentes internos (avaliação de necessidades; planejamento e execução; e avaliação) como também com os componentes externos, que correspondem aos demais sistemas da área de gestão de pessoas (recrutamento e seleção, avaliação de desempenho, programas de ascensão funcional etc.).

Em relação ao conceito de Desenvolvimento, Nadler (1984) salienta que ele compreende a aprendizagem voltada para o crescimento individual, sem relação com um trabalho específico, envolvendo experiências organizadas de aprendizagem, em um período definido de tempo para aumentar a possibilidade de melhoria da performance no trabalho e do crescimento. Educação, por sua vez, é considerada conceitualmente como uma aprendizagem mais ampla que aquelas denominadas como Treinamento e Desenvolvimento.

198 Pontual (1980, p.5) define Educação como "todos os processos pelos quais as pessoas adquirem compreensão do mundo, bem como capacidade para lidar com seus problemas". Porém, Borges-Andrade (2002) afirma que a separação dos conceitos Treinamento e Desenvolvimento está tênue, pois o aumento da demanda cognitiva nos postos de trabalho e a sofisticação das exigências de aprendizado têm levado à quase extinção das ações puramente de Treinamento.

Vários pesquisadores desenvolveram modelos teóricos e empíricos para avaliação dos resultados das ações de TD\&E. Os principais modelos internacionais apontados pela literatura são: o de Kirkpatrick (1976), o de Hamblin (1978); e o Modelo Integrado de Avaliação e Efetividade de Treinamento (IMTEE), proposto por Alvarez, Salas e Garofano (2004). No Brasil, há dois modelos de pesquisa de TD\&E preponderantes: o Modelo de Avaliação Integrado e Somativo (MAIS), criado por Borges-Andrade (1982) e o Modelo Integrado de Avaliação do Impacto do Treinamento no Trabalho (IMPACT), elaborado por Abbad (1999).

Tanto no modelo IMTEE, como no MAIS e no IMPACT há pressuposições de que características da clientela, que contêm informações demográficas, funcionais, motivacionais e atitudinais relativas aos participantes dos treinamentos, sejam preditoras dos resultados obtidos nas ações de capacitação. Esses modelos fortalecem, portanto, a necessidade de se investigar variáveis como as crenças sobre o sistema de TD\&E e também outras variáveis de características da clientela como idade, tempo de empresa, experiência de trabalho, salário, motivação e autoeficácia. Borges-Andrade (1982) explica, inclusive, que os insumos referem-se aos fatores físicos, sociais e aos estados comportamentais e cognitivos, anteriores à instrução, que podem afetá-lo ou aos seus resultados. Portanto, o autor já previa que variáveis como nível socioeconômico dos treinandos; idade desses participantes; crenças de que são capazes de obter sucesso; uso de estratégias de autorregulação, entre outras, poderiam afetar os resultados dos treinamentos realizados. Diversas pesquisas no Brasil e no exterior confirmaram que as características da clientela são de fato importantes preditoras da aprendizagem, da reação e do impacto do treinamento no trabalho (Abbad, 1999; Alvarez et al., 2004; Pilati \& BorgesAndrade, 2004; Salas \& Cannon-Bowers, 2001; Tannenbaum \&Yukl, 1992). 
A análise das pesquisas aqui apresentadas mostra que não há resultados conclusivos sobre o poder de predição das variáveis crenças sobre o sistema de TD\&E, embora as características da clientela estejam claramente ligadas aos resultados obtidos nessas ações de capacitação. Assim, definiu-se que tais variáveis dariam uma contribuição se incluídas no modelo de pesquisa.

\section{Crenças sobre o sistema de TD\&E}

Crenças são estruturas cognitivas básicas sobre as quais as atitudes se fundamentam (Ajzen \& Fishbein, 1980). O conceito de crença adotado neste estudo tem como ponto de partida a concepção apresentada, (Krüger, 2004) segundo a qual crenças são concebidas como sendo quaisquer assertivas ou proposições aceitas por pelo menos uma pessoa. No conceito do autor, "as crenças são representações simbólicas, comumente baseadas em linguagens naturais, que têm sua origem na experiência pessoal e afirmam uma relação entre objetos concretos e abstratos, ou propriedades a eles atribuídas". Por conseguinte, esse conceito de crença diferencia-se da concepção encontrada no senso comum, que concebe as crenças como algo relacionado à fé religiosa ou à própria religião. Krüger (2004) explica que as crenças podem ser tanto pessoais (como a avaliação feita por uma pessoa a respeito de outra) quanto socialmente compartilhadas (como a opinião pública e os estereótipos sociais).

Independentemente do conceito adotado, o pressuposto básico no estudo das crenças é o da sua organização lógica, subjetiva, em sistemas ou conjuntos logicamente estruturados, sendo capazes de ativar motivações e, portanto, condutas sociais influenciando por essa via processos coletivos. Ou seja, os sistemas de crenças propiciam àqueles que os desenvolveram e aceitam uma interpretação relativamente estável e significativa da realidade física, social e cultural, tomada como referência. Nesse sentido, é possível supor que tais crenças influenciem comportamentos das pessoas, como no caso das crenças sobre o sistema de treinamento de uma organização.

Portanto, para os autores citados, as crenças variam de pessoa para pessoa, são mutáveis e estão relacionadas às experiências de cada indivíduo e ao contexto sócio-cultural com o qual interagem. Assim, as crenças podem ser intuitivas e na maioria das vezes são implícitas. De forma simplificada, pode-se dizer que a fonte de todas as crenças é a experiência. As experiências ocorrem naturalmente na vida na medida em que as pessoas participam de interações sociais que se diversificam em termos de sua estrutura, duração e intensidade. Segundo Alencar (2005), a crença é originada por meio de um processo de construção social, incorporação de ideias de outras pessoas, com interferência de aspectos do ambiente e circunstâncias.

Um aspecto relevante ressaltado por Alencar (2005) é o de que as crenças selecionam as informações recebidas, moldam, combinam com outras informações, de forma a gerar crenças mais consistentes. Em outras palavras, as crenças tendem a ir se modificando, na medida em que as pessoas vão recebendo mais informações e passando por diferentes experiências ao longo da vida, gerando, inclusive, uma resistência à mudança, com o processo de consolidação das crenças. Porém, essa construção não é apenas individual. As crenças são formuladas em diferentes culturas ou grupos de pessoas a partir do momento em que as pessoas se inserem nas diversas instituições apresentadas pela sociedade, como escola, família, religião e organizações de trabalho.

Em resumo, as crenças tendem a ser organizadas, adquirindo formas de teoria, doutrinas, argumentos e sistemas de opinião e pensamento, cuja aceitação fica condicionada por fatores e critérios diversos, pessoais, objetivos e lógicos. Assim, crenças podem ser compreendidas como elementos de representação mental, abstratos, oriundos de experiências individuais e coletivas que, uma vez alcançando o formato e o suporte físico necessário à sua objetivação, oferecem-se à crítica.

O estudo da possível influência das variáveis demográficas e funcionais sobre crenças acerca do Sistema de Treinamento, Desenvolvimento e Educação apóia-se em algumas dessas concepções sobre as crenças: a) o fato de elas poderem ser compartilhadas; b) ganharem força na medida em que mais pessoas compartilham da mesma crença; e c) serem capazes de levar os indivíduos a mudanças. Portanto, é razoável supor que as crenças que uma pessoa tem sobre o sistema de Treinamento, Desenvolvimento e Educação 
possam ser influenciadas pelo tempo de trabalho na empresa ou pelo fato de já ter trabalhado em outras organizações.

De acordo com Freitas (2005), as crenças são fundamentais para promover mudança de atitudes já estabelecidas. Para a autora, para formar novas atitudes ou para modificar atitudes já existentes, as intervenções passariam, necessariamente, pela aquisição de novas informações sobre o objeto, isto é, pela reconfiguração das crenças. Portanto, é de fundamental importância haver nas organizações instrumentos desenvolvidos e validados que possibilitem identificar as crenças existentes sobre determinado fenômeno, como é o caso do Sistema de Treinamento.

Nas organizações, quando novos funcionários são contratados, os próprios colegas de trabalho começam a conversar sobre suas crenças acerca do Sistema de TD\&E daquela instituição, relatando, por exemplo, que o Treinamento é algo importante naquela empresa, que ajuda a desenvolver atividades na prática e que é considerado nas promoções ou outras crenças contrárias a estas. Quando essas crenças são compartilhadas com esses novos empregados, boa parte dos novatos tomará essas falas como verdades e passará a interpretar o Treinamento naquela instituição da forma como lhe foi relatada pelos funcionários antigos, resultando em uma crença coletiva em relação ao Treinamento. Com base nessa premissa, a presente pesquisa procurou investigar se as crenças sobre o Sistema de TD\&E são influenciadas por características demográficas e funcionais.

Apesar do número reduzido de pesquisas realizadas sobre o assunto em questão, foram encontrados alguns resultados das investigações sobre crenças em relação ao treinamento e à aprendizagem. Freitas (2005) realizou uma pesquisa sobre o impacto de treinamento nos desempenhos do indivíduo e do grupo de trabalho e os relacionou com crenças sobre o sistema de treinamento e com o suporte à aprendizagem contínua. Para a construção da escala sobre crenças em relação ao sistema de treinamento, a autora utilizou três bases conceituais: as escalas de Cinismo Organizacional desenvolvidas porTesluk, Faar, Mathieu e Vance (1995); as crenças sobre Treinamento indicadas por Freitas, (2005); e o Modelo MAIS de Borges-Andrade (1982) que contempla

200 diversos componentes do Sistema de TD\&E. A escala elaborada por Freitas e Borges-Andrade (2004) foi dividida em três fatores: crenças sobre as contribuições do treinamento para o indivíduo e para a organização; crenças sobre o processo de levantamento de necessidades de treinamento; e crenças sobre os resultados e processos de treinamento. Os resultados encontrados por Freitas (2005) apontam que as crenças sobre as contribuições do treinamento para o indivíduo e para a organização estão significativa e positivamente relacionadas ao impacto do treinamento no trabalho. A pesquisa sinaliza para a necessidade de maior atenção em relação às crenças dos funcionários sobre o Sistema de TD\&E para que o impacto aconteça de forma mais positiva, indo ao encontro dos objetivos organizacionais.

Os resultados das pesquisas mostradas por Cheng e Ho (2001) indicaram que várias atitudes do treinando afetam o grau em que ele transfere para o contexto de trabalho o que aprendeu em treinamento. Segundo Freitas (2005), essas atitudes são decorrentes de crenças existentes em vários níveis. Crenças sobre a própria pessoa (auto-eficácia); sobre o trabalho (nível de envolvimento, planejamento de carreira, expectativas quanto aos benefícios do treinamento); e crenças sobre a empresa (cinismo organizacional - uma descrença generalizada sobre a capacidade de mudança na organização). Ou seja, Cheng e Ho (2001) também encon-traram resultados de pesquisa que sinalizam para a importância e a influência das crenças relativas a TD\&E.

Outro estudo realizado por Alencar (2005) teve como objetivo verificar as influências de crenças relacionadas ao trabalho no surgimento de sintomas na saúde dos trabalhadores e influências na produtividade no setor de frangos de corte, na região do Paraná. 0 autor relatou análises qualitativas que apontaram para associações entre as crenças: "o trabalho é ruim", "o trabalho não é prazeroso", "a empresa não é séria", "adoece-se facilmente no ambiente de trabalho", e "o trabalho não dá alegria" entre outros, e a incidência de sintomas relacionados à saúde. Os resultados obtidos indicaram ainda que os níveis de mortalidade das aves foram mais baixos nas granjas supervisionadas pelo profissional que tinha nível mais alto de satisfação no trabalho e crenças como "depende de mim o resultado do lote", "a empresa é séria”,"os frangos sofrem durante a criação", e ainda "é preciso treinamento para criar frangos". Os resultados sinalizam que, em uma das granjas, 
há descrença em relação à organização, talvez resultando em uma aprendizagem negativa ou na falta da mesma, devido à desmotivação em relação ao trabalho e à realização da tarefa. Os resultados também sugerem que a aprendizagem pode ser mais eficaz, quando os funcionários acreditam na importância e na necessidade do Treinamento.

Vale também destacar o estudo realizado por Gonçalves (2008) com o objetivo de investigar se as expectativas em relação ao treinamento são preditoras do impacto do treinamento no trabalho. As expectativas sobre o sistema de treinamento correspondem a um construto correlato às crenças sobre o sistema de TD\&E e, portanto, importante para a compreensão dos resultados da pesquisa apresentada no presente artigo. A pesquisa de Gonçalves foi realizada em uma autarquia federal, com aplicação de 472 questionários antes do evento de capacitação para medição das expectativas em relação ao treinamento e 296 questionários cerca de quatro meses após o término do curso, para avaliação do impacto do treinamento no nível do comportamento no cargo. A autora validou uma escala de expectativas sobre ações de TD\&E cuja estrutura final ficou com dois fatores: expectativa de utilidade e melhoria de performance e expectativa de melhoria além da performance. Gonçalves (2008) encontrou como preditores da expectativa em relação a treinamento quatro variáveis: gênero, escolaridade e cargo, sendo que as mulheres e os funcionários com escolaridade mais baixa e os ocupantes de cargos de nível mais baixo tendem a apresentar médias mais altas de expectativas. Além disso, as expectativas de melhoria além da performance também atuaram como preditoras do impacto do treinamento no trabalho, o que reforça os achados de Freitas e Borges-Andrade (2004).

Assim, considerando a revisão de literatura realizada, a hipótese central definida para a presente pesquisa foi: "Idade, tempo de empresa, experiência em treinamento em outras organizações e salário são preditores das crenças em relação às ações de TD\&E". Assim, esperava-se que os mais velhos, os funcionários com menor tempo de empresa, as pessoas com mais experiência em treinamento e os que recebem maiores salários tivessem crenças mais positivas sobre o sistema de TD\&E.

\section{Método}

O delineamento metodológico foi de um estudo correlacional, de análise multivariada. A amostra foi composta por 220 funcionários de sete empresas privadas do Estado do Rio de Janeiro. Todos os respondentes foram voluntários e concordaram em participar da pesquisa, com direito a acesso aos resultados gerais da mesma. O estudo foi aprovado pelo Comitê de Ética em Pesquisa da Universidade Salgado de Oliveira, protocolo no 184/2007, em 29/11/2007, e todos os participantes assinaram um Termo de Consentimento Livre e Esclarecido, antes de sua inclusão na amostra.

Em relação às organizações pesquisadas, duas tinham até 5 anos de atuação no mercado, uma tinha 10 anos de atuação no Brasil e quase 20 de atuação em outros países e as quatro outras organizações tinham mais de 25 anos de existência. Em relação à gestão, três eram de natureza familiar e quatro não. As cidades onde essas empresas foram pesquisadas foram: Rio de Janeiro, Rio das Ostras, Pádua, Campos dos Goytacazes, Niterói e Macaé. Em relação ao tipo de treinamento, dois tinham natureza claramente técnica, três referiam-se a atendimento a clientes e os outros tinham natureza mais comportamental. O tempo de duração dos treinamentos variou de 6 a 20 horas, tendo sido treinados ao todo entre 15 e 600 funcionários. Em relação aos instrutores que atuaram nesses cursos, em apenas dois foram instrutores internos, sendo os outros cinco ministrados por instrutores externos.

O perfil predominante dos participantes da pesquisa foi de homens (59,1\%), com ensino médio (63,8\%), experiência em treinamento em outras organizações (63,6\%), mais de um ano de trabalho (51,8\%), idade média de 31 anos (Desvio-Padrão - DP=8,97) e salário na faixa de 5 salários-mínimos.

Como instrumento de coleta de dados foi utilizada a Escala de Crenças sobre o Sistema Treinamento, desenvolvida e validada por Freitas e Borges-Andrade (2004). A Escala de Crenças sobre o Sistema Treinamento possui 36 itens e para cada item os participantes atribuíram uma pontuação de 1 a 10, sendo 1 ancorado na afirmação "Não Acredito" e 10 na afirmação "Acredito Totalmente". A Escala de Crenças sobre o Sistema Treinamento foi originalmente testada por Freitas e Borges- 
-Andrade (2004) em uma amostra de aproximadamente 385 funcionários do Banco do Brasil. Os autores identificaram a presença de três componentes ou fatores na escala: Fator 1) Crenças sobre as contribuições do treinamento para o indivíduo e para a organização, Fator 2) Crenças sobre o processo de levantamento de necessidades de treinamento e Fator 3) Crenças sobre os resultados e o processo de treinamento. Os coeficientes de fidedignidade (Alfa de Cronbach) reportados para esses fatores foram 0,94,0,84 e 0,82, respectivamente. No presente estudo, foram utilizados os mesmos fatores sugeridos por Freitas e Borges-Andrade (2004). Os coeficientes de fidedignidade observados neste estudo para os três fatores foram adequados e semelhantes aos reportados nos estudos originais: 0,93, 0,85 e 0,87, respectivamente.

A coleta de dados desta pesquisa foi feita com aplicação pessoal, nas sete empresas, antes da realização de treinamentos, de um questionário com a escala de crenças sobre o Sistema de TD\&E e com as perguntas relativas às variáveis sexo, idade, escolaridade, tempo de empresa, experiência de treinamento em outras organizações e salário.

Em relação à análise foi feita a limpeza do banco de dados com o objetivo de identificar possíveis valores incorretos na digitação dos dados, bem como a presença de dados omissos (missing values) e outliers univariados (boxplot) e multivariados (Distância Mahalanobis). Também foram avaliadas a normalidade, a homogeneidade de variância, a multicolinearidade e feita a análise de resíduos. Algumas variáveis tiveram que ser transformadas. O critério numérico utilizado para avaliar a necessidade de transformações foi ancorado na simetria. Variáveis foram transformadas sempre que o escore-Z para simetria (simetria/erro padrão de medida da simetria) foi maior que 1,96 (Tabachnick \& Fidell, 1996).

Foi necessário efetuar transformações nas seguintes variáveis: crenças sobre o sistema de TD\&E - fatores 1 e 3 . Essas transformações resolveram satisfatoriamente os problemas de simetria, de curtose e de heterogeneidade de variância. Após as transformações foram identificados nove casos de valores extremos univariados, os quais foram seletivamente excluídos das análises. As demais variáveis não apresentaram anomalias dignas de nota. As variáveis transformadas foram utilizadas em todas as análises de correlação e regressão. Para clarificar a interpretação dos resultados, são apresentadas as médias e os desvios-padrão das variáveis antes da transformação (Tabachnick \& Fidell, 1996).

\section{Resultados}

Inicialmente, foram conduzidas análises, com o software GPower (Faul, Erdfelder, Lang \& Buchner, 2007) para verificar se o tamanho da amostra seria suficiente para garantir potência estatística aos testes. Verificou-se que com um $n \geq 197$ seria possível detectar correlações relativamente fracas (iguais ou superiores que $0,25)$ considerando os parâmetros normalmente recomendados na literatura $(\alpha=0,05, \beta=0,05)$. Como os testes conduzidos envolveram amostras acima de 200 sujeitos, a potência das análises esteve acima de 0,95. Ainda sobre a adequação do tamanho da amostra, o mesmo atendeu às duas fórmulas (Tabachinick \& Fidel, 1996) recomendadas para análises de regressão.

A análise dos escores da escala de crenças sobre o Sistema de Treinamento permitiu concluir que os treinandos possuem uma crença positiva em relação às ações educacionais. Foi possível observar esse resultado a partir da média obtida tanto nos escores da escala geral $(M=7,9)$, como nos escores dos três fatores: crenças sobre contribuições do treinamento, crenças sobre levantamento de necessidades e sobre resultados e crenças sobre os processos e os resultados do treinamento (Tabela 1).

Foram realizadas correlações de Pearson e de Spearman (para as variáveis não-paramétricas). As correlações bivariadas apontaram relações significativas para

Tabela 1. Escores da escala de crenças e de seus fatores.

\begin{tabular}{lcccc}
\hline $\begin{array}{l}\text { Escala de Crenças } \\
\text { Escala Tipo Likert (1 a 10) }\end{array}$ & Min & Max & M & DP \\
\hline $\begin{array}{l}\text { Crenças sobre o Sistema Treina- } \\
\text { mento (Escala completa) }\end{array}$ & 2,4 & 9,8 & 7,9 & 1,2 \\
$\begin{array}{l}\text { Crenças sobre contribuições do } \\
\text { treinamento (Fator 1) }\end{array}$ & 2,3 & 10,0 & 8,2 & 1,2 \\
$\begin{array}{l}\text { Crenças sobre levantamento de } \\
\text { necessidades (Fator 2) }\end{array}$ & & & & \\
Crenças sobre resultados (Fator 3) & 2,7 & 10,0 & 7,2 & 1,6 \\
\hline
\end{tabular}

Min: miníma; Max: máxima; M: média; DP: desvio-padrão. 
todos os pares de variáveis, exceto para experiência prévia em TD\&E e as crenças sobre as contribuições do treinamento para o indivíduo e para a organização (Fator 1). As correlações foram baixas, variando de 0,15 a 0,31.

Finalmente, para concluir o teste da hipótese de pesquisa foram realizadas análises de regressão múltipla padrão. Foram realizadas três regressões, cada uma delas tendo como variável dependente um dos três fatores da escala de crenças sobre o sistema de TD\&E. As variáveis independentes foram as mesmas para as três regressões: idade, tempo de serviço (variável dummy), experiência prévia em treinamento (variável dummy) e salário.

O Fator 1, Crenças sobre as contribuições do treinamento para o indivíduo e para a organização, teve como preditores o salário $(\beta=0,22)$, a experiência prévia com ações de treinamento em outras organizações $(\beta=0,17)$ e o tempo de trabalho $(\beta=0,19)$, sendo que quanto maior o salário, quando há experiência prévia com treinamento e quanto maior o tempo de trabalho, mais favoráveis tendem a ser as crenças sobre as contribuições do treinamento. A variável idade não permaneceu no modelo. O poder explicativo do modelo foi relativamente baixo ( $R^{2}$ ajustado=0,15), (Tabela 2 ).

No que diz respeito ao Fator 2, Crenças sobre o processo de levantamento de necessidades de treinamento, o modelo apontou como variáveis preditoras: salário $(\beta=0,18)$ e a experiência prévia com ações de treinamento em outras organizações $(\beta=0,18)$, sendo que quanto maior o salário e quando há experiência prévia com treinamento, mais favoráveis tendem a ser as crenças sobre o processo de levantamento de necessidades de treinamento. As variáveis idade e tempo de trabalho não permaneceram neste modelo, cujo $R^{2}$ ajustado também foi modesto $(0,11)$. A Tabela 3 apresenta

Tabela 2. Regressão sobre as crenças sobre as contribuições do treinamento para o indivíduo e para a organização.

\begin{tabular}{lccc}
\hline Variáveis & $\mathrm{B}$ & $\boldsymbol{\beta}$ & $\mathrm{Sr}^{2}$ \\
\hline Experiência prévia & $0,146^{*}$ & 0,171 & 0,068 \\
Tempo de trabalho & $-0,016^{*}$ & $-0,191$ & 0,008 \\
Salário & $0,000^{* *}$ & $-0,218$ & 0,000 \\
Idade & $-0,004$ & $-0,088$ & 0,004 \\
\hline
\end{tabular}

Média=8,16; DP:1,18; $F=7,33 ; R=0,42 ; R^{2}=0,17 ; R^{2}$ ajustado=0,15. ${ }^{*} p<0,05 ;{ }^{* *} p<0,01$. os resultados da regressão linear sobre as crenças sobre o processo de levantamento de necessidades de treinamento.

Finalmente, na regressão do Fator 3, Crenças sobre os resultados e o processo de treinamento, o modelo apontou o salário $(\beta=0,21)$ e a idade $(\beta=0,20)$ como variáveis preditoras, sendo que quanto maior o salário e a idade, mais favoráveis tendem a ser as crenças sobre os resultados e o processo de treinamento. As variáveis tempo de trabalho e experiência prévia em TD\&E não permaneceram neste modelo, cujo $R^{2}$ ajustado também foi modesto $(0,10)$. A Tabela 4 apresenta os resultados da regressão linear sobre as crenças sobre os resultados e o processo de treinamento.

\section{Discussão}

O presente estudo partia de uma hipótese de que idade, tempo de empresa, experiência em treinamento e faixa salarial seriam preditores das crenças em relação às ações de TD\&E e da aprendizagem. A análise do conjunto desses resultados sinaliza que a hipótese que pressupunha as características da clientela como variáveis preditoras das crenças sobre o sistema de TD\&E

Tabela 3. Regressão sobre as crenças sobre o processo de levantamento de necessidades de treinamento.

\begin{tabular}{lccc}
\hline Variáveis & $\mathrm{B}$ & $\beta$ & $\mathrm{sr}^{2}$ \\
\hline Experiência prévia & $0,547^{*}$ & 0,175 & 0,254 \\
Tempo de trabalho & 0,024 & 0,079 & 0,030 \\
Salário & $0,000^{*}$ & 0,181 & 0,000 \\
Idade & 0,023 & 0,148 & 0,015 \\
\hline
\end{tabular}

Média=7,24; DP:1,56; $F=5,54 ; R=0,37 ; R^{2}=0,14 ; R^{2}$ ajustado=0,11. ${ }^{*} p<0,05 ;{ }^{* *} p<0,01$.

Tabela 4. Regressão sobre as crenças sobre os resultados e o processo de treinamento.

\begin{tabular}{lccc}
\hline Variáveis & $\mathrm{B}$ & $\boldsymbol{\beta}$ & \multicolumn{1}{c}{$\mathrm{sr}^{2}$} \\
\hline Experiência prévia & 0,094 & 0,099 & 0,077 \\
Tempo de trabalho & $-0,001$ & $-0,015$ & 0,009 \\
Salário & $0,000^{* *}$ & 0,213 & 0,000 \\
Idade & $0,009^{*}$ & 0,199 & 0,005 \\
\hline
\end{tabular}

Média=7,98; DP:1,31; $F=5,10 ; R=0,36 ; R^{2}=0,13 ; R^{2}$ ajustado=0,10. ${ }^{*} p<0,05 ;{ }^{* *} p<0,01$. 
foi parcialmente confirmada, pois nem todas as variáveis pessoais permaneceram como preditoras. A análise de regressão para as crenças sobre as contribuições do treinamento para o indivíduo e para a organização tiveram como preditores o salário $(\beta=0,22)$, a experiência prévia com ações de treinamento em outras organizações $(\beta=0,17)$ e o tempo de trabalho $(\beta=0,19)$. As crenças sobre o processo de levantamento de necessidades de treinamento tiveram como preditores o salário $(\beta=0,18)$ e a experiência em treinamento em outras organizações $(\beta=0,18)$, sendo que os que têm menos experiência e maiores salários apresentam crenças mais favoráveis. Já para as crenças sobre os resultados e o processo de treinamento, as variáveis preditoras foram salário $(\beta=0,21)$ e idade $(\beta=0,20)$. Em relação ao salário - única variável presente nos três modelos relativos a crenças sobre o sistema de treinamento - esse resultado pode ser explicado pelo maior grau de consciência que as pessoas com salários mais altos têm sobre a importância da aprendizagem no ambiente organizacional. Porém, o poder preditivo dos modelos foi baixo com $R^{2}$ ajustado variando de 0,15; 0,11 e 0,10, respectivamente para os Fatores 1, 2 e 3 da Escala de Crenças sobre o Sistema de Treinamento.

No que se refere à influência da experiência prévia em TD\&E sobre as crenças no sistema de treinamento, é importante sinalizar que as crenças são formadas não só na organização atual onde o indivíduo trabalha, mas por todas as possíveis experiências anteriores que ele tenha vivenciado. Assim, o fato de pessoas que tenham experiências prévias com treinamento terem crenças mais positivas acerca do processo de levantamento de necessidades de treinamento e das contribuições do treinamento para o indivíduo e para a organização é um indicador positivo para as organizações, pois sinaliza que as experiências de capacitação em outras organizações têm sido favoráveis. Porém, é preocupante o fato de que as crenças sobre os resultados e o processo de treinamento não apresentem diferenças significativas entre quem já participou de treinamentos em outras organizações e quem não participou. Esse resultado sugere que a participação em ações educacionais não tem levado a um aumento das crenças acerca dos resultados e do processo de treina-

204 mento.
Sobre as crenças sobre o sistema de TD\&E não se encontrou na literatura nacional e estrangeira nenhum estudo que associasse o construto a variáveis de características de clientela. Entretanto, levando-se em conta a própria definição de crenças como representações mentais oriundas de experiências individuais e coletivas, era de esperar que as características da clientela explicassem os resultados de crenças. De fato, a experiência de trabalho influencia as crenças acerca do Sistema de TD\&E e é possível que outras variáveis de características pessoais e funcionais não incluídas no presente estudo, tais como lócus de controle, cargo ocupado, comprometimento organizacional e grau de escolaridade, também expliquem o construto.

Em relação ao salário, encontrou-se que, mesmo com baixo poder preditivo do modelo, essa variável está significativa e positivamente relacionada aos três fatores da escala de crenças. Esse resultado não surpreende uma vez que são exaustivos os estudos do Instituto Brasileiro de Geografia e Estatística (IBGE), correlacionando nível educacional e rendimentos salariais no Brasil. Portanto, o fato de quem está mais preparado em termos de qualificação para o trabalho ter acesso a maior renda proveniente deste suscita corrobora a hipótese de que o salário tenha algum poder de predição sobre as crenças acerca do sistema de treinamento das organizações.

No que diz respeito à idade, os resultados da pesquisa apontam que as pessoas mais velhas e que têm mais experiência de trabalho tendem a ter crenças mais positivas sobre o sistema de treinamento. Isso indica que, além da experiência de trabalho, também a experiência de vida contribui para a percepção favorável das ações de capacitação oferecidas pelas organizações, sobretudo no que diz respeito às crenças relativas às contribuições para o indivíduo e para a organização (Fator 1) e sobre as crenças relativas ao levantamento de necessidades de treinamento (Fator 2). Contudo, vale ressaltar que Gonçalves (2008) não encontrou relações significativas ao tentar correlacionar idade com as expectativas que os treinandos têm antes de realizar um curso de treinamento. Ou seja, é possível que as pessoas mais velhas sejam mais otimistas em relação às crenças relativas ao sistema de treinamento, o que não significa que as mesmas terão sempre expectativas 
mais favoráveis para todos os cursos que Ihe forem oferecidos.

Quanto aos escores da escala de crenças sobre o Sistema de Treinamento, eles indicam crenças positivas dos trabalhadores das sete empresas em relação às ações educacionais. Resultado semelhante em termos de escores foi obtido por Freitas (2005), que, ao contrário da presente pesquisa, focou uma instituição de natureza pública.

Assim, os resultados encontrados sustentam a hipótese geral desta pesquisa, quando ela afirma que a experiência prévia em treinamento, o tempo de trabalho, a idade e o salário são preditores das crenças sobre o sistema de TD\&E. O fato de os que já foram treinados em outras organizações e os que recebem maiores salários possuírem crenças mais positivas sobre o sistema de TD\&E, confirma a hipótese do estudo. Assim, a experiência de trabalho, o salário, a idade e o tempo de trabalho têm influência nas crenças relativas aos Sistemas de Treinamento (Figura 1).

Um aspecto que precisa ser ressaltado é o fato de que variáveis contingenciais não controladas - tais como tipo de treinamento, qualidade do instrutor, tamanho da empresa, setor de atuação e cultura organizacional - podem exercer influência sobre os resultados encontrados na presente pesquisa sendo recomendável a inclusão desse tipo de variável em outros estudos a fim de que se possa aprimorar o modelo ora testado.

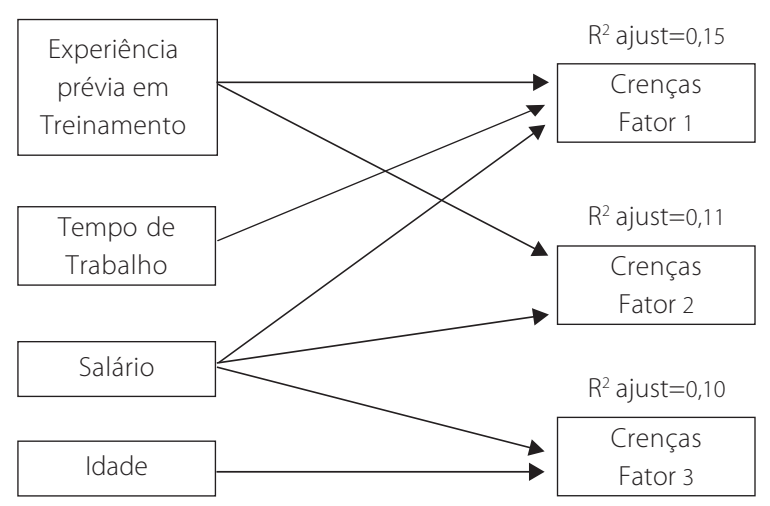

Figura 1. Modelo final para a variável crenças sobre o sistema de TD\&E.

\section{Considerações Finais}

Algumas crenças influenciam a atitude das pessoas em direção a um dado comportamento. Isso ocorre porque a pessoa acredita que a exibição daquele comportamento levará a certas consequências, que aquela pessoa avalia como importantes (teoria da expectância). Por exemplo, acreditar que participar de treinamentos pode resultar na promoção no cargo ou no aumento de salário. Outro tipo de crença que também direciona o comportamento é a de natureza normativa, isto é, as pessoas esperam que determinado comportamento seja ou não exibido. Por exemplo, pode haver uma crença de que tudo que foi aprendido em treinamento será aplicado no trabalho. Alguns estudos, relacionam crenças mais positivas sobre o sistema de TD\&E a um maior impacto das ações de treinamento sobre o desempenho no trabalho.

Para entender as variáveis que poderiam explicar crenças mais positivas ou mais negativas sobre o sistema de TD\&E investigou-se o poder preditivo das variáveis idade, tempo de trabalho, experiência prévia em treinamento e salário. Os resultados permitem concluir que as quatro variáveis influenciam nas crenças sobre o sistema de treinamento, embora apenas o salário tenha permanecido nos três modelos estudados.

Entre as limitações deste trabalho encontra-se a amostra reduzida de organizações (sete empresas), a baixa variabilidade em termos de faixa etária e de tempo de trabalho na instituição. Em parte, tais aspectos se justificam pelo perfil de participante escolhido para essa pesquisa - os trabalhadores com mais baixa escolaridade - entre os quais há maior rotatividade e um perfil de sujeitos mais jovens.

Entre as contribuições está o fato de o estudo incluir profissionais com diferentes níveis de escolaridade, com significativa presença de trabalhadores com baixa escolaridade (ensino fundamental e médio), uma vez que a maioria das pesquisas brasileiras sobre o tema costuma ser realizada com participantes predominantemente de nível superior. Do ponto de vista conceitual, a pesquisa também contribui na medida em que aponta variáveis preditoras das crenças sobre o sistema de TD\&E, permitindo aos profissionais que atuam em gestão de pessoas promoverem comunicações diferenciadas para aqueles que tendem a 
apresentar crenças mais negativas sobre o sistema de TD\&E, considerando que tais crenças costumam influenciar no impacto do treinamento no trabalho (Freitas, 2005).

Em relação a futuras pesquisas na área, sugere-se investigar se as crenças em relação à imagem do professor/instrutor e em relação à organização influenciam a motivação para aprender e a aprendizagem. Como o suporte do supervisor tem sido considerado um dos aspectos mais importantes para o impacto do treinamento no trabalho, poder-se-ia investigar se as crenças sobre o sistema de TD\&E mediam ou moderam os efeitos desse suporte sobre os níveis de avaliação do Treinamento (reação, aprendizagem e impacto).

Por fim, os resultados da presente pesquisa podem suscitar alguns questionamentos nos profissionais que atuam na área, de forma a instigar que eles revejam as suas práticas, tanto as relativas ao sistema de TD\&E como as afetas aos demais sistemas de gestão de pessoas.

\section{Referências}

Abbad, G. S. (1999). Um modelo integrado de avaliação do impacto do treinamento no trabalho - IMPACT. Tese de doutorado não-publicada, Universidade de Brasília.

Ajzen, I., \& Fisbein, M. (1980). Understanding attitudes and predicting social behavior. Englewood Cliffs: N.J. PrenticeHall.

Alencar, M. D. C. D. (2005). Associações entre crenças relacionadas ao trabalho e suas influências na Saúde dos trabalhadores e na produtividade, no setor de produção de frangos de corte: uma abordagem ergonômica. Tese de doutorado não-publicada, Universidade Federal de Santa Catarina, Florianópolis.

Alvarez, K., Salas, E., \& Garofano, C. M. (2004). An integrated model of training evaluation and effectiveness. Human Resource Development Review, 3 (4), 385-416.

Borges-Andrade, J. E. (1982). Avaliação somativa de sistemas instrucionais: integração de três propostas. Tecnologia Educacional, 11 (46), 29-39.

Borges-Andrade, J. E. (1996). Treinamento de pessoal: em busca de conhecimento e tecnologia relevantes para as organizações. In A. Tamayo, J. E. Borges-Andrade \& Codo (Orgs.), Trabalho, organizações e cultura (pp.129-149). São Paulo: Cooperetiva de Autores Associados.

Borges-Andrade, J. E. (2002). Desenvolvimento de medidas em avaliação de treinamento. Estudos de Psicologia (Natal), 7 (Número especial), 31-43.
Cheng, E. W. K., \& Ho, D. C. K. (2001). A review of transfer of training studies in the past decade. Personnel Review, 30 (1), 102-118.

Faul, F., Erdfelder, E., Lang, A. G., \& Buchner, A. (2007). G*Power 3: a flexible statistical power analysis program for the social, behavioral, and biomedical sciences. Behavior Research Methods, 39 (2), 175-191.

Freitas, I. A. (2005). Impacto de treinamento nos desempenhos do indivíduo e do grupo de trabalho: suas relações com crenças sobre o sistema de treinamento e suporte à aprendizagem contínua. Tese de doutorado não-publicada, Universidade de Brasília.

Freitas, I. A., \& Borges-Andrade, J. E. (2004). Desenvolvimento e validação de escala de crenças sobre o sistema de treinamento. Estudos de Psicologia (Natal), 9 (3), 479-488.

Gonçalves, A. I. P. (2008). Avaliação de Treinamento: a expectativa e a reação do treinando como preditoras do impacto no trabalho. Dissertação de mestrado não-publicada, Universidade Salgado de Oliveira, Niterói.

Hamblin, A. C. (1978). Avaliação e controle do treinamento. São Paulo: McGraw-Hill do Brasil.

Kirkpatrick, D. L. (1976). Evaluation of training. In R. L. Craig (Org.), Training and development handbook ( $2^{\text {nd }}$ ed.). New York: McGraw-Hill.

Krüger, H. (2004). Cognição, estereótipos e preconceitos sociais. In M. O. Lima \& M. E. Pereira. Estereótipos, preconceitos ediscriminação: perspectivas teóricas emetodológicas. Brasil: EDUFBA.

Nadler, L. (1984). The handbook of human resources development. New York: Wiley.

Pilati, R., \& Borges-Andrade, J. E. (2004). Estudo empírico dos antecedentes de medidas de impacto do treinamento no trabalho. Revista Psicologia: Teoria e Pesquisa, 20 (1), 31-38.

Pontual M. (1980). Evolução do treinamento empresarial. In G. G. Boog (Org.), Manual de treinamento edesenvolvimento (pp.5-11). São Paulo: McGraw-Hill.

Salas, E., \& Cannon-Bowers, J. (2001). The science of training: a decade of progress. Annual Review Psychology, 52, 471-499.

Tabachinick, B. G., \& Fidell, L. S. (1996). Using multivariate statistics. New York: Harper Collins.

Tannenbaum, S. I., \& Yukl, G. (1992). Training and development in work organizations. Annual Review of Psychology, 43, 399-441.

Tesluk, P. E., Farr, J. L., Mathieu, J. E. \& Vance, R. J. (1995). Generalization of employee involvement training to the job setting: individual and situational effects. Personnel Psychology, 48, 607-632.

Recebido em: 5/11/2009

Versão final reapresentada em: 23/11/2009

Aprovado em: 7/1/2010 